\title{
Analyzing the cost of medical student virtual conference registration by specialty during the COVID-19 pandemic
}

https://doi.org/10.1515/jom-2021-0117

Received April 14, 2021; accepted June 18, 2021;

published online July 9, 2021

\begin{abstract}
Context: Medical student involvement in research is an important metric used by residency programs across most specialties to better assess the candidates' commitment to advancing medicine as well as their specialty of interest. One strategy is presentation of research work at national conferences in the specialty of interest; another is simply attending these events for networking purposes with program directors. However, attending these conferences carries cost.
\end{abstract}

Objectives: To investigate the cost incurred by medical students to attend the premier annual scientific meeting of each major medical specialty in 2020, during the novel coronavirus 2019 (COVID-19) pandemic, and to evaluate whether "research intensive" specialties carried greater conference registration costs.

Methods: Potential medical specialties to which students can apply upon graduation were identified in the National Residency Match Program (NRMP). "Research intensive" specialties were defined as those with a mean number of abstracts, presentations, or publications $\geq 10$ per matched applicant in the 2020 NRMP. The premier conference for each specialty was determined by membership in the American Medical Association House of Delegates in the NRMP. The cost to be a member of each conference's parent organization and attend the annual meeting were determined by internet search. Subgroup analysis was conducted to compare cost between research intensive and non research intensive specialties.

\footnotetext{
*Corresponding author: Daniel Veyg, BS, OMS III, New York Institute of Technology College of Osteopathic Medicine, 101 Northern Boulevard, 11545 Glen Head, NY, USA, E-mail: dveyg@nyit.edu Robert Gurevich, BBA, MS III, SUNY Downstate Health Sciences University School of Medicine, New York, NY, USA
}

Results: The registration cost of 19 virtual conferences held in 2020 were analyzed in this study. The average cost to attend as a medical student member of the hosting organization for all conferences was \$49.82 (range, \$0-\$331; $\mathrm{SD} \pm \$ 92.18$ ), while the average cost to attend as a nonmember across all conferences was $\$ 188.16$ (range, \$0-\$595; SD \pm \$176.35; p<0.001). Seven of $19(36.8 \%)$ meetings had free registration for medical students who are members of the hosting organization. The premier meetings affiliated with the seven research intensive specialties had a significantly higher mean cost for medical students who were members of the parent organization than the meetings of the other specialties ( $\$ 125.60$ vs. $\$ 49.20$; $\mathrm{p}=0.031$ ). There was no significant difference in mean registration cost between research intensive and non research intensive specialty conference registration for nonmember medical students $(\mathrm{p}=0.85)$. Vascular surgery, radiation oncology, and emergency medicine were the three specialties with the most expensive medical student member registration fees overall (\$331, \$200, and \$195, respectively).

Conclusions: Medical student attendance and presentation at national scientific meetings was found to be significantly more costly for research intensive specialties, although all meetings were held in an online format due to the COVID-19 pandemic. Overall, this reflects an increased financial burden to an already indebted medical student population and compounds the stresses brought on by the pandemic. More national medical societies might consider free meeting registration to reflect support for medical students and encourage their continued participation in research to advance their specialty of interest.

Keywords: medical education; research; residency match.

Historically, medical students at all levels of training make generous and gratuitous contributions to academic research [1]. Generally, there are two reasons a medical student is involved in research during their medical education: to bolster their residency application and to garner a more intimate understanding about a topic that relates to 
their future desired specialty [1, 2]. Involvement in research as a medical student is considered an important experience by program directors and is ranked highly as one of the key factors that determines how prospective programs ranks candidates [3]. Certain specialties are subjectively known for emphasizing research more than others, and specialties with a higher number of mean research accomplishments per matched applicant are considered more "competitive" due to the arduous nature of research and the commitment required to successfully complete and publish or present multiple projects before submitting a residency application. Osteopathic medical students are in a unique position in this sense, given that they present and publish less research work, on average, than their allopathic counterparts [4]. However, NRMP data suggests that osteopathic medical students often publish and present research at greater volumes than their peers in medical specialties that place an emphasis on research [4]. This is likely due to osteopathic medical students seeking ways to objectively bolster their applications in fields that may traditionally not be welcoming to osteopathic students, out of a desire to demonstrate their commitment to program directors in those specialties. Research is an important component for all medical students undergoing the residency application process.

While participating in research shows commitment and perseverance, true value lies in the number of publications and conference presentations a student is able to produce; these activities offer program directors an objective metric to stratify candidates during the residency selection process. Presenting research at national conferences is considered more prestigious than presentations at local or regional events. However, these ventures come at a cost to medical students. Although publication costs are often covered by the primary investigator of the research project, the cost of traveling to and registering for research conferences is largely left to the student.

In 2020, the novel coronavirus 2019 (COVID-19) pandemic brought a halt to the tradition of live meetings, and all conferences were held in virtual formats. Live meetings traditionally varied in price for medical students, ranging from no cost up to nearly one thousand dollars for registration, but the cost variance for virtual meetings has been less studied. We therefore undertook this study to analyze the registration cost of the premier conference during the COVID-19 pandemic for each medical specialty to which medical students could apply to in the National Residency Match Program (NRMP). The primary endpoints were member and nonmember registration costs for medical students. The secondary endpoints were to the relationship between conference registration cost and "research intensive" specialty status, to determine whether any relationship existed.

\section{Methods}

The NRMP website was accessed by both authors in January 2021 to establish a list of the specialties to which a medical student could apply in the NRMP. Using the 2020 Charting Outcomes in the Match report published by the NRMP, we identified "research intensive" specialties as those specialties with a mean number of abstracts, presentations, or publications $\geq 10$ per matched applicant in the 2020 Match [4]. Next, we determined the "premier" national medical conference for each of the specialties by membership in the American Medical Association House of Delegates [5]. Again, only organizations representing a specialty to which a medical student could apply to in the NRMP match were included; to make this selection, we matched each specialty in the NRMP to the national society that contained the specific specialty in its name. We did not include any subspecialty organizations in this analysis.

After identifying the premier annual meeting for each specialty, we performed another internet search in January 2021 to determine the cost for a medical student to register for each event, both as a member of the parent organization and as a nonmember. If the conference did not readily display this information on their website for the 2020 meeting, the Wayback Machine Google Chrome extension was utilized to search for past versions of the website [6-20]. If the pricing was still not available, we contacted the conference organizers directly via email to request the cost for medical student registration. All searches conducted in this study were performed via the Google Chrome internet browser.

The cost of member and nonmember medical student conference registration was aggregated for each conference identified. We also performed a subgroup analysis by stratifying specialties along with their associated conference into research intensive or non research intensive according to our established definitions. The results are reported below as means, ranges, and standard deviations. A paired two tailed $t$ test was used to determine significance between medical student member and nonmember registration costs. An unpaired two tailed $t$ test was used to determine significance in the subgroup analysis comparing research intensive specialties to non research intensive specialties. All calculations were performed in Microsoft Excel, and significance was set at $\mathrm{p}=0.05$.

This study did not require Institutional Review Board approval, as all information was obtained from public sources, and no personal information from human subjects was involved.

\section{Results}

Twenty two specialties were identified in the 2020 NRMP match, and each specialty was appropriately matched to its respective premier conference. Three specialties (internal medicine, neurosurgery, and neurology) had cancelled their respective main 2020 annual scientific meetings, resulting in a final analysis of 19 fully virtual meetings 
Table 1: Parent organizations of medical specialties included in the analysis as well as cost associated to attend as a medical student member and nonmember of the organization. Asterisks denote research intensive specialties.

\begin{tabular}{|c|c|c|c|c|}
\hline Specialty & Parent organization & $\begin{array}{r}\text { Nonmember } \\
\text { registration } \\
\text { (\$) }\end{array}$ & $\begin{array}{r}\text { Member } \\
\text { registration } \\
(\$)\end{array}$ & Source \\
\hline Anesthesiology & American Society of Anesthesiologists & 399 & 0 & 6 \\
\hline Child neurology & Child Neurology Society & 50 & 50 & 7 \\
\hline Dermatology* & American Academy of Dermatology & 90 & 90 & 8 \\
\hline Diagnostic radiology & Radiologic Society of North America & 325 & 0 & 9 \\
\hline Emergency medicine & American College of Emergency Physicians & 595 & 195 & 10 \\
\hline Family medicine & American Academy of Family Medicine & 130 & 130 & Email \\
\hline General surgery & American College of Surgeons & 0 & 0 & Email \\
\hline Interventional radiology* & Society of Interventional Radiology & 0 & 0 & Author registration \\
\hline Obstetrics and gynecology & American College of Obstetricians and Gynecologists & 150 & 0 & 11 \\
\hline Osteopathic medicine & Osteopathic Medical Education & 100 & 100 & 12 \\
\hline Orthopaedic surgery* & American Academy of Orthopaedic Surgeons & 300 & 100 & 13 \\
\hline Otolaryngology* & $\begin{array}{l}\text { American Academy of Otolaryngology-Head and Neck } \\
\text { Surgery }\end{array}$ & 300 & 158 & Author registration \\
\hline Pathology & College of American Pathologists & 0 & 0 & 14 \\
\hline Pediatrics & American Academy of Pediatrics & 450 & 25 & 15 \\
\hline $\begin{array}{l}\text { Physical medicine and } \\
\text { rehabilitation }\end{array}$ & $\begin{array}{l}\text { American Academy of Physical Medicine and } \\
\text { Rehabilitation }\end{array}$ & 100 & 75 & 16 \\
\hline Plastic surgery* & American Society of Plastic Surgeons & 0 & 0 & 17 \\
\hline Psychiatry & American Psychiatric Association & 30 & 15 & 18 \\
\hline Radiation oncology* & American Society for Radiation Oncology & 225 & 200 & 19 \\
\hline Vascular surgery* & Society of Vascular Surgery & 331 & 331 & 20 \\
\hline Mean & & 188.16 & 48.94 & $p<0.001$ \\
\hline Standard deviation & & 176.35 & 92.18 & \\
\hline
\end{tabular}

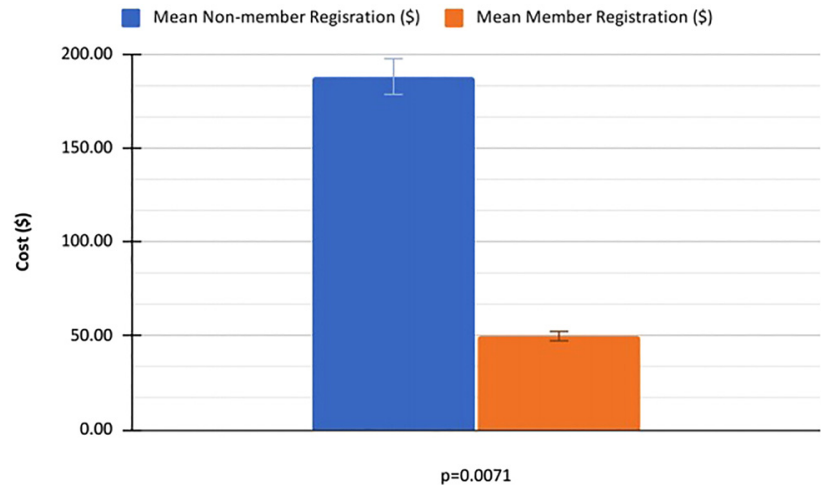

Figure 1: Comparison of mean conference registration cost between medical student members and non-members of conference parent organization $(p<0.01)$.

(Table 1). The mean registration cost for medical students who were not a member of the hosting organization was $\$ 188.20$ (range, $\$ 0-\$ 595 ; \mathrm{SD} \pm \$ 176.4$ ). The mean registration cost for medical students who were members of the hosting organization was $\$ 49.80$ (range, $\$ 0-\$ 331$; $\mathrm{SD} \pm$ \$92.2; $\mathrm{p}<0.001$; Figure 1). Seven (36.8\%) meetings offered free registration for medical students who were members of the hosting organization, while only four
(15.7\%) meetings were offered for free to nonmember medical students.

Of the 19 specialties included in the analysis, seven were categorized as research intensive: dermatology, interventional radiology, orthopedic surgery, otolaryngology, plastic surgery, radiation oncology, and vascular surgery. The premier meetings affiliated with these seven specialties had a significantly higher mean cost for medical students who were members of the parent organization than the meetings of the other specialties ( $\$ 125.60$ vs. $\$ 49.20 ; \mathrm{p}=0.031$; Figure 2). Vascular surgery, radiation oncology, and emergency medicine were the three specialties with the most expensive medical student member meeting registration fees ( $\$ 331, \$ 200, \$ 195$, respectively). For medical student nonmembers, the most expensive meetings were for emergency medicine, pediatrics, and anesthesiology ( $\$ 595, \$ 450, \$ 399$, respectively).

\section{Discussion}

To our knowledge, no prior studies have investigated the cost of medical student conference attendance during the 

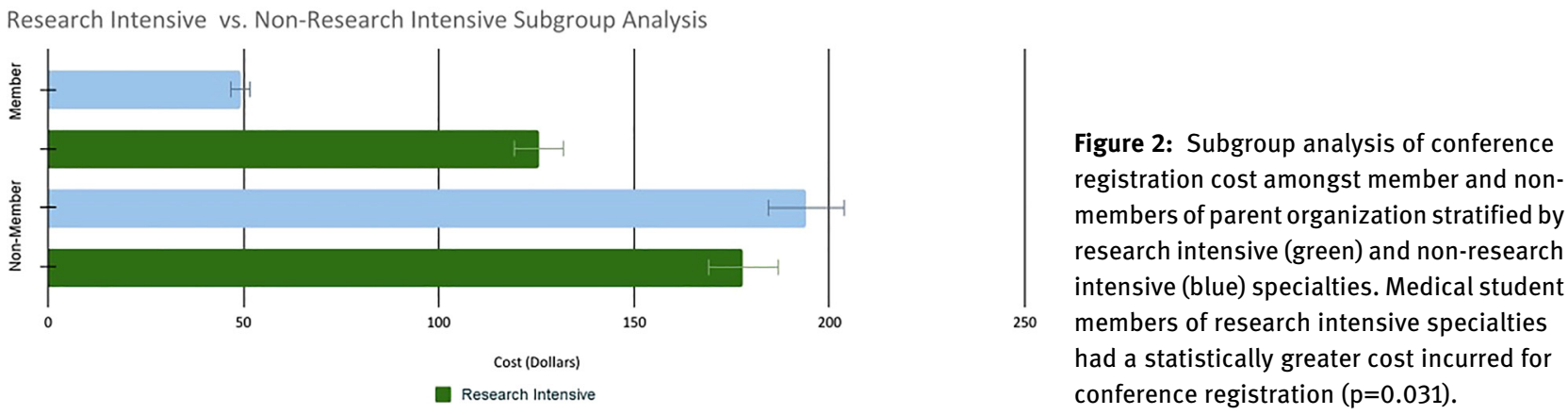

COVID-19 pandemic, a period during which all national medical meetings analyzed in this study were held in an online or "virtual" format. While this change did limit the costs associated with traveling to conference events and other associated expenses, the cost to attend a virtual event remained questionable. Presenting research work on a national level at a high impact meeting serves as an important component when forming a competitive residency application [1-3]. Research accomplishments are directly correlated with higher chances of a residency match for both osteopathic and allopathic medical students, and this is especially true in more competitive specialties [4, 21]. National meetings also serve as platforms for students to network with program directors and other noteworthy individuals within their specialty of interest. Students who do not attend these meetings, either due to a lack of research to present or inability to fund the registration cost, are thus disadvantaged. This poses a major challenge to the already indebted medical student population, and particularly impacts the underprivileged. In $2016,76 \%$ of all medical school graduates had education debt, and the mean amount of debt that year was $\$ 190,000$ amongst MD and DO students combined [22]. This number has continued to climb, as cost of attendance increases at an average rate of approximately $2 \%$ per year [22].

Our initial analysis showed that medical students who are members of the parent organization benefit from statistically significant lower registration costs for these annual meetings. Membership fees vary amongst different organizations, but often provide other benefits aside from lower registration fees, such as access to educational materials, mentorship, and forums for voicing questions. Our subgroup analysis revealed that conferences affiliated with the seven research intensive specialties in the NRMP match had a statistically significant greater cost of attendance for medical students who were members of the parent organization. Specialties that value medical student research contributions have greater cost incurred to students that wish to attend their meetings, which perpetuates the exclusivity and inequity associated with these fields. This also suggests a potential barrier for students of low socioeconomic status who are interested in pursuing research intensive specialties. While some medical schools have funding to support student research projects and conference attendance, this may be merit based. Additionally, the amount of funding varies tremendously amongst medical schools. Moreover, the main costs associated with traditional conference attendance are travel, food, and lodging. These factors were not considered in this analysis, given the virtual nature of meetings in 2020, but should be noted as another significant aspect (and even barrier) for medical students. Additional studies should be conducted to illustrate whether our findings correlate with registration costs of live meetings. More conferences can be analyzed to determine associations between cost and subjective prestige of meetings, as local or regional conferences can still offer good opportunities for medical students to present their work.

\section{Limitations}

Our study had several limitations. For some specialties, multiple primary governing bodies exist, and although we attempted to be as objective as possible when making the decision to select one organization over another, readers may disagree regarding our final choices. The premier conferences affiliated with two notably research intensive specialties (ophthalmology and urology) were not analyzed, as they are independent of the NRMP Match, and their respective organizations do not publicize the average research accomplishments of matched and unmatched candidates. Additionally, registration cost data for the annual premier neurosurgery meeting was also excluded, because the hosting organization had cancelled its 2020 meeting. This should be noted, as neurosurgery is the most research intensive specialty in the NRMP Match. Another limitation is that we only analyzed member and nonmember medical student registration fees; other associated costs such as travel, lodging, and food expenses 
were not included. Additionally, late registration fees were not included; given the time constraints on research, it may not always be possible to register early, thus incurring greater cost for the student. We also focused on American conferences; the conferences associated with international organizations for each specialty were not considered. Finally, we did not investigate medical school financial support options for these conferences, which can vary widely. Additional studies should be conducted to address these limitations.

\section{Conclusions}

Medical student attendance and presentation at premier national scientific meetings was found to be significantly more costly for research intensive specialties, although all meetings in 2020 were held in an online format due to the COVID-19 pandemic. Overall, this reflects an increased financial burden on an already indebted medical student population and compounds the stresses brought on by the pandemic; free conference registration would reflect an understanding of this burden. We suggest that national medical societies should consider free meeting registration to reflect support for medical students and encourage their continued participation in research to advance their specialty of interest. Given the inherent value of presenting research for the fate of a medical student in the context of a competitive residency match process, eliminating these financial biases would allow for more equitable opportunity for medical students of all backgrounds to demonstrate their work to residency programs on a national level.

\section{Research funding: None reported.}

Author contributions: Both authors provided substantial contributions to conception and design, acquisition of data, or analysis and interpretation of data; both authors drafted the article or revised it critically for important intellectual content; both authors gave final approval of the version of the article to be published; and both authors agree to be accountable for all aspects of the work in ensuring that questions related to the accuracy or integrity of any part of the work are appropriately investigated and resolved.

\section{Competing interests: None reported.}

\section{References}

1. Amgad M, Man Kin Tsui M, Liptrott SJ, Shash E. Medical student research: an integrated mixed-methods systematic review and meta-analysis. PloS One 2015;10:e0127470.
2. Cruser DA, Dubin B, Brown SK, Bakken LL, Licciardone JC, Podawiltz AL, et al. Biomedical research competencies for osteopathic medical students. Osteopath Med Prim Care 2009; 3:10.

3. NRMP. Results of the 2020 NRMP program director survey; 2020. Available from: www.nrmp.org [Accessed 26 Jan 2020].

4. NRMP. Results and data 2020 main residency match; 2020. Available from: www.nrmp.org [Accessed 17 Jan 2020].

5. American Medical Association. Member organizations of the AMA house of delegates; 2018. Available from: https://www.amaassn.org/house-delegates/hod-organization/memberorganizations-ama-house-delegates.

6. American Society of Anaesthesiologists. FAQs - frequently asked questions. Annual meeting 2020. Available from: https://www.asahq.org/annualmeeting/attend/faqs [Accessed 14 Jan 2020].

7. Child Neurology Society. 2020 CNS-ICNA conjoint meeting. Available from: https://www.childneurologysociety.org/ meetings/future-cns-annual-meetings [Accessed 14 Jan 2020].

8. American Academy of Dermatology. 2020 AAD annual meeting fees, session access, and eligibility. Available from: https:// assets.ctfassets.net/1ny4yoiyrqia/6b45IJ3c7YYsW8JM0gXuZD/ 111e62bb85f419d89efbc727e84b1b23/AM20-Reg-Session-Fees. pdf [Accessed 14 Jan 2020].

9. Virtual ACEP 2020. Visit ACEPs corporate website. (n.d.). Available from: https://www.acep.org/acep20/virtual/ [Accessed 14 Jan 2020].

10. Radiologic Society of North America. Pricing and registration; 2020. Available from: https://www.rsna.org/annual-meeting/ pricing-and-registration?gclid=Cj0KCQjwgtWDBhDZARIsADEKwg MlaWc4Hlw2b7c1cg6B00w1700WLiF8Qjg3Ee02 hLvYMuYZ-rVplcaAnMbEALw_wcB [Accessed 14 Jan 2020].

11. American Osteopathic Association (AOA). Register for OMED; 2020. https://web.archive.org/web/20210124054739/https:// omed.osteopathic.org/register-for-omed-2020/ [Accessed 14 Jan 2020].

12. American College Gynecology. ACOG 2020-registration and fees. Available from: https://www.acog.org/education-and-events/ meetings/acog-2020-virtual-conference/registration-and-fees [Accessed 14 Jan 2020].

13. American Academy of Orthopedic Surgeons. Registration rates. Available from: https://www.aaos.org/globalassets/annualmeeting/registration/am20_registration-rates.pdf [Accessed 14 Jan 2020].

14. College of American Pathologists. CAP20 virtual-knowledge relationships expertise. Available from: https://learn.cap. org/lms/activity?@curriculum.id=-1\&@activity.id= 6893948\&@activity.bundleActivityld=-1 [Accessed 14 Jan 2020].

15. American Academy of Pediatrics. 2020 virtual national conference. Available from: https://shop.aap.org/ 2020-national-conference-exhibition-virtual/ [Accessed 14 Jan 2021].

16. AAPM\&R. Virtual assembly registration form. Available from: https://www.aapmr.org/docs/default-source/annual-assemblydocuments/aa20-regform-final.pdf?sfvrsn $=c 7345 f 7 c \_4$ [Accessed 14 Jan 2021]. 
17. American Society of Plastic Surgery. Registration pricing. Plastic surgery, the meeting. Available from: https://web.archive.org/ web/20200809025145/https://www.plasticsurgerythemeeting. com/registration/pricing [Accessed 14 Jan 2021].

18. American Psychiatric Association. American Psychiatric Association 2020 meeting; 2020. Available from: https:// convention.apa.org/apa-2020 [Accessed 14 Jan 2021].

19. Register - 2020 ASTRO Annual Meeting - American Society for Radiation Oncology (ASTRO) - American Society for Radiation Oncology (ASTRO). Astro.org; 2021. Available from: https://www. astro.org/Meetings-and-Education/Micro-Sites/2020/AnnualMeeting/Register [Accessed 14 Jan 2021].
20. SVS Vascular Annual Meeting. Vascular.org; 2020. Available from: https://vascular.org/sites/default/files/20_VAM_ registration_fees.pdf [Accessed 14 Jan 2021].

21. Matthews CN, Estrada DC, George-Weinstein M, Claeson KM, Roberts MB. Evaluating the influence of research on match success for osteopathic and allopathic applicants to residency programs. J Am Osteopath Assoc 2019;119:588-96.

22. Youngclaus J, Bunton S. An updated look at attendance cost and medical student debt at U.S. medical schools; 2017. https:// www.aamc.org/data-reports/analysis-brief/report/updatedlook-attendance-cost-and-medical-student-debt-us-medicalschools. 